\title{
Arsenic Adsorption on Lanthanum-Impregnated Activated Alumina: Spectroscopic and DFT Study
}

\author{
Qiantao Shi, ${ }^{\dagger}$ Li Yan, ${ }^{\dagger}$ Tingshan Chan, ${ }^{\ddagger}$ and Chuanyong Jing ${ }^{*} \dagger$
}

${ }^{\dagger}$ State Key Laboratory of Environmental Chemistry and Ecotoxicology, Research Center for Eco-Environmental Sciences, Chinese Academy of Sciences, Beijing 100085, China

${ }^{\ddagger}$ National Synchrotron Radiation Research Center, 101 Hsin-Ann Road, Hsinchu Science Park, Hsinchu 30076, Taiwan

Supporting Information

ABSTRACT: Rare earth-modified adsorbents (REMAs) have been widely used to remove oxyanion pollutants from water, including arsenic (As). However, the molecular-level structural information and reactions at the liquid/solid interface are still murky, which limits the design of applicable REMAs. Herein, a lanthanum-impregnated activated alumina (LAA) was synthesized as a representative REMA, and its As uptake mechanisms were explored using multiple complementary characterization techniques. Our adsorption experiments showed that LAA exhibited 2-3 times higher As adsorption capacity than AA. In contrast to the bidentate configuration formed on most metal oxide surfaces, our EXAFS and DFT results suggest that As(III) and As(V) form monodentate surface complexes on LAA through As-O-La coordinative bonding. In situ flow cell ATR-FTIR observed

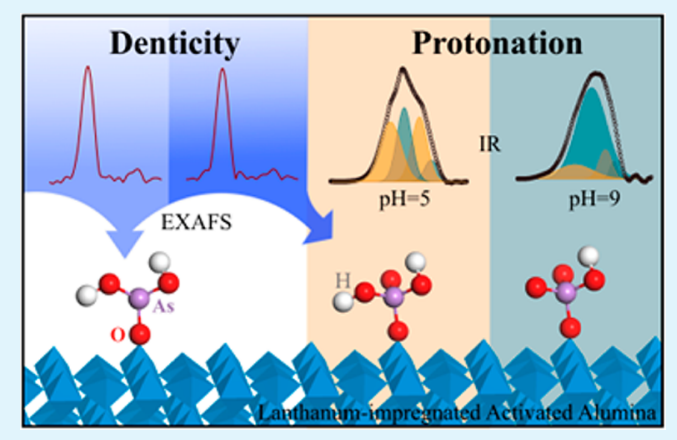
a strong dependence of As-O peak positions on $\mathrm{pH}$, which could be interpreted as the change in the fractions of As(V) surface complexes with zero- to double-protonation on LAA, AA, and $\mathrm{LaOOH}$. As (V) on LAA existed as singly and doubly protonated surface species, and the $\mathrm{pK}_{\mathrm{a}}$ of transition from double to single protonation ( 5.8) was lower than that for its soluble counterpart (6.97). The surface reaction and structural configuration were incorporated in a CD-MUSIC model to satisfactorily predict macroscopic As adsorption behaviors. The insights gained from the molecular-level reactions shed light on the design and application of REMAs in environmental remediation for As and its structural analogues.

KEYWORDS: adsorption, arsenic, coordination modes, surface chemistry, lanthanum

\section{INTRODUCTION}

Adsorption using hybrid materials has been demonstrated to be an effective technique to remove hazardous materials from water due to its easy operation, low cost, and high efficiency. ${ }^{1,2}$ Recent advances in hybrid materials highlight the fact that rare earth-modified adsorbents (REMAs) may substantially enhance the removal of oxyanions, including arsenic (As), phosphate, selenite, and chromate (Table S1). ${ }^{1-5}$ Although their promising performance has been reported in many publications, the mechanism of oxyanion adsorption on REMAs is generalized as ligand exchange based on infrared (IR) and X-ray photoelectron spectroscopy (XPS) studies. ${ }^{6-8}$ This simplified model lacks molecular-level structural information on the coordination geometry and protonation of the surface species, which is fundamental to be able to design and fabricate REMAs and predict their performance.

For exploration of the molecular-level surface reaction mechanisms, multiple complementary spectroscopic techniques should be employed. For example, extended X-ray adsorption fine structure (EXAFS) and Fourier transform infrared (FTIR) spectroscopies have been used to explain why As(V) adsorption could be enhanced on an iron-cerium $(\mathrm{Fe}-\mathrm{Ce})$ bimetal oxide REMA. $^{8,9}$ Their results show that As $(\mathrm{V})$ is covalently bonded with $\mathrm{Fe}$ instead of $\mathrm{Ce}$ on REMA. ${ }^{9}$ The addition of $\mathrm{Ce}$ in iron oxides, alternatively, contributes to the destruction of the magnetite crystal phase and the formation of an amorphous $\mathrm{Fe}-\mathrm{Ce}$ structure. ${ }^{8}$ However, this explanation had difficulty interpreting the enhanced As removal efficacy of REMAs without iron oxides. ${ }^{7,10-12}$

Lanthanum (La)-impregnated activated alumina (LAA), an example of a REMA, has demonstrated advantages over activated alumina (AA) in $\mathrm{F}$ adsorption efficiency, applicable $\mathrm{pH}$ range, and $\mathrm{Al}$ leachability. ${ }^{13}$ Meanwhile, a simple physical mixing of lanthanum oxide with AA was found to substantially enhance the As adsorption capacity. ${ }^{14}$ These observations promote the hypothesis that the rare earth elements in REMAs, such as La in LAA, may provide additional adsorption sites with different adsorption mechanisms from those of its supporting materials.

The purpose of this study was to investigate the molecularlevel adsorption structure and reaction mechanism of As on LAA. Density function theory (DFT) calculations, EXAFS, and in situ flow cell attenuated total reflectance (ATR) FTIR spectroscopy were used. The surface reactions were incorpo-

Received: September 15, 2015

Accepted: November 13, 2015

Published: November 13, 2015 

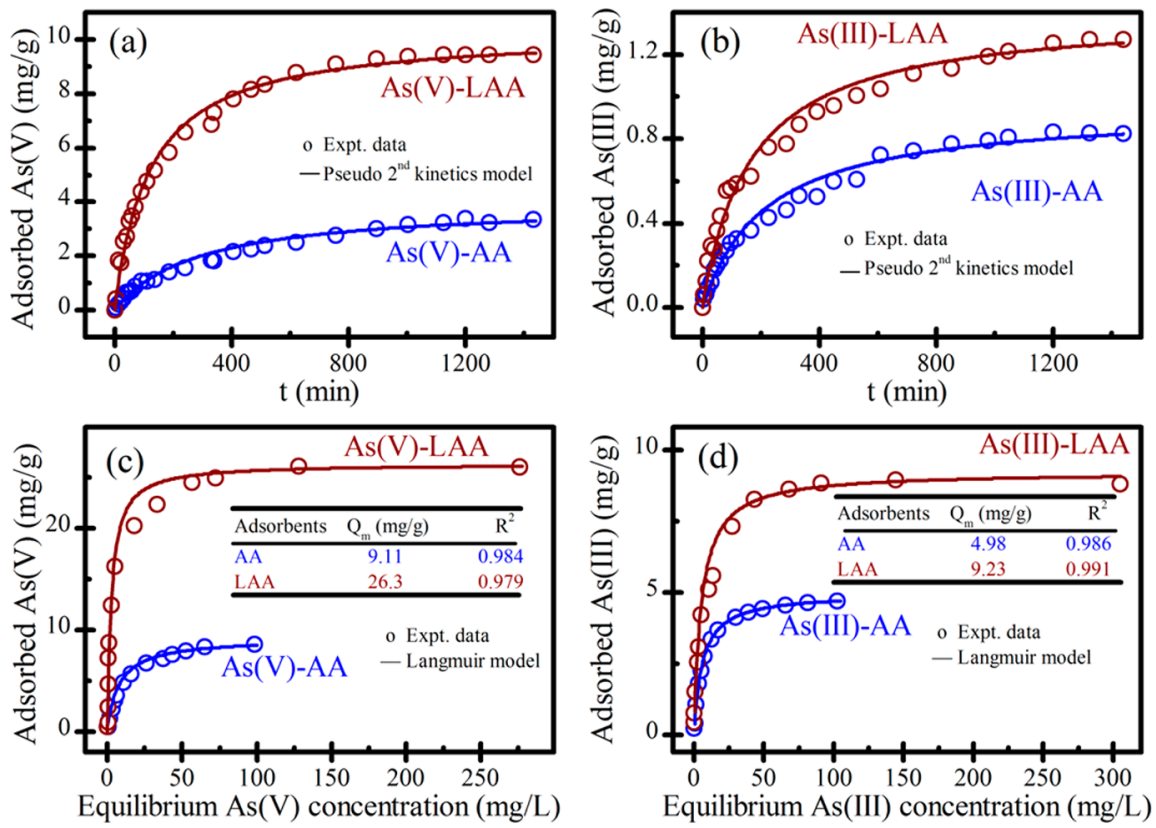

Figure 1. (a, b) Kinetics and (c, d) isotherms for (a, c) As(V) and (b, d) As(III) adsorption on $1 \mathrm{~g} / \mathrm{L}$ of AA (blue) and LAA (red) in 0.01 mol/L $\mathrm{NaCl}$ solution at $\mathrm{pH} \mathrm{7}$; (inset) the tables in (c) and (d) show the parameters of the Langmuir model; temperature $=25 \pm 2{ }^{\circ} \mathrm{C}$.

rated in the charge distribution multisite surface complexation (CD-MUSIC) model to simulate the As adsorption behaviors. The results of our work shed new light on the interaction mechanisms of As and its structural analogues with REMAs, which is fundamental to be able to design and implement REMAs for environmental remediation.

\section{MATERIALS AND METHOD}

Materials. Stock solutions of $1,000 \mathrm{mg} / \mathrm{L} \mathrm{As}(\mathrm{III})$ and $\mathrm{As}(\mathrm{V})$ were prepared by dissolving $1.733 \mathrm{~g}$ of $\mathrm{NaAsO}_{2}$ and $5.653 \mathrm{~g}$ of $\mathrm{Na}_{3} \mathrm{AsO}_{4}$. $12 \mathrm{H}_{2} \mathrm{O}$ in $1 \mathrm{~L}$ of deionized (DI) water (18.2 $\mathrm{M} \Omega$, Milli-Q), respectively. The La stock solution was prepared by dissolving $19.485 \mathrm{~g}$ of analytical grade $\mathrm{La}\left(\mathrm{NO}_{3}\right)_{3} \cdot 6 \mathrm{H}_{2} \mathrm{O}$ in $50 \mathrm{~mL}$ of DI water, and the $\mathrm{pH}$ was adjusted to 6.0 using $\mathrm{NH}_{3} \cdot \mathrm{H}_{2} \mathrm{O}$. All regents were purchased from Sinopharm, China. Granular activated alumina (AA) optimized for As removal with a diameter of 1-3 $\mathrm{mm}$ (Keyuan, China) was used without further purification.

Preparation of LAA and $\mathrm{LaOOH}$. LAA and lanthanum oxyhydroxide $(\mathrm{LaOOH})$ were prepared using the method described in our previous report. ${ }^{13}$ Briefly, to impregnate La on AA, a mixture of $10 \mathrm{~mL}$ of La stock solution and $14.5 \mathrm{~g}$ of AA was sonicated for $4 \mathrm{~h}$. The solid was separated, dried at $328 \mathrm{~K}$, and then calcined at $573 \mathrm{~K}$ for $4 \mathrm{~h}$. After the obtained material was cooled, it was washed with DI water until the conductivity of the wash water was below $100 \mu \mathrm{S} / \mathrm{cm}$. The impregnation process was repeated five times. $\mathrm{LaOOH}$ was synthesized using the same process in the absence of AA.

Adsorption Experiments. Batch adsorption experiments were conducted to compare the effectiveness of the adsorbents. In a typical experiment, $0.1 \mathrm{~g}$ samples of adsorbents were mixed with $100 \mathrm{~mL}$ of As solution at desired $\mathrm{pH}$ values. The samples were mixed on a rotary shaker at $200 \mathrm{rpm}$ at $298 \mathrm{~K}$ for $24 \mathrm{~h}$ and then centrifuged and filtered through a $0.45 \mu \mathrm{m}$ membrane filter for analysis. A background electrolyte of $0.01 \mathrm{~mol} / \mathrm{L} \mathrm{NaCl}$ was used in the experiment. $\mathrm{HCl}$ and $\mathrm{NaOH}$ were used to adjust the $\mathrm{pH}$.

The As(III) and As(V) adsorption isotherms on AA and LAA were investigated at $\mathrm{pH}$ 7. The adsorbent concentration was fixed at $1 \mathrm{~g} / \mathrm{L}$, and the $\mathrm{As}(\mathrm{III})$ and $\mathrm{As}(\mathrm{V})$ concentrations were increased to 100 and $300 \mathrm{mg} / \mathrm{L}$, respectively. The adsorption kinetics on AA and LAA were also studied at $\mathrm{pH} 7$ in $1 \mathrm{~L}$ of $0.01 \mathrm{~mol} / \mathrm{L} \mathrm{NaCl}$ solution with $10 \mathrm{mg} / \mathrm{L}$ of $\mathrm{As}(\mathrm{V})$ or $5 \mathrm{mg} / \mathrm{L}$ of $\mathrm{As}(\mathrm{III})$. The As concentration and speciation were determined by high performance liquid chromatography atomic fluorescence spectrometry (HPLC-AFS, Jitian, China).

Zeta $(\zeta)$ Potential Measurements. The $\zeta$ potential was measured using a Zetasizer Nano ZS (Malvern Instrument Ltd., UK). All experiments were performed under $\mathrm{N}_{2}$ atmosphere to eliminate $\mathrm{CO}_{2}$ from the system. The $\mathrm{pH}$ of the suspension containing $0.1 \mathrm{~g} / \mathrm{L}$ of adsorbent in $0.01 \mathrm{~mol} / \mathrm{L} \mathrm{NaCl}$ was adjusted from 6.5 to 12.0 using 0.1 $\mathrm{mol} / \mathrm{L} \mathrm{NaOH}$ and $\mathrm{HCl}$ solutions. Suspension samples were placed on a rotating shaker for $24 \mathrm{~h}$, and the final $\mathrm{pH}$ was measured. The reported $\zeta$ potential values were the average of three measurements and are shown in Figure S1. The results showed that the points of the zero charge (PZC) for AA, LAA, and $\mathrm{LaOOH}$ were 7.9, 8.9, and 9.1, respectively.

XAS Analysis. The EXAFS samples were prepared using batch adsorption experiments with $100 \mathrm{mg} / \mathrm{L}$ of $\mathrm{As}(\mathrm{III})$ or $300 \mathrm{mg} / \mathrm{L}$ of As $(\mathrm{V})$ in the presence of $1 \mathrm{~g} / \mathrm{L}$ of AA, LAA, or $\mathrm{LaOOH}$ in $0.01 \mathrm{~mol} / \mathrm{L}$ $\mathrm{NaCl}$ solution at $\mathrm{pH}$ 7. The As K-edge spectra were collected at beamline $01 \mathrm{Cl}$ at the National Synchrotron Radiation Research Center (NSRRC) in Taiwan. An energy range of -200 to $1000 \mathrm{eV}$ from the K-edge was used to acquire the spectra with a standard Lytle detector at cryogenic temperatures $(<20 \mathrm{~K})$ using a helium cryostat to prevent beam-induced oxidation. Three to six scans were collected from each sample, inspected for overall quality, and averaged to improve the signal/noise ratio. The EXAFS data analysis was performed using the ATHENA and ARTEMIS programs in the Demeter computer package. ${ }^{15,16}$ The analysis procedure was similar to our previous studies ${ }^{17,18}$ and is detailed in the Supporting Information.

In Situ Flow Cell ATR-FTIR Study. The in situ flow cell ATRFTIR measurements were performed using a Thermo-Nicolet Nexus 6700 FTIR spectrometer equipped with a horizontal attenuated total reflectance (HATR) cell (PIKE Tech) and a liquid nitrogen-cooled mercury-cadmium-telluride (MCT) detector. A multibounce $\mathrm{ZnSe}$ ATR crystal with $45^{\circ}$ beveled faces (infrared angle of incidence, $\theta$ ) was used, and the infrared spectra were collected using 256 scans per spectrum at a resolution of $4 \mathrm{~cm}^{-1}$.

The collection and treatment for the spectra of $\mathrm{As}(\mathrm{V})$ adsorption on $\mathrm{AA}, \mathrm{LAA}$, and $\mathrm{LaOOH}$ were similar to those described in our previous publications. ${ }^{19,20}$ Briefly, the adsorbent film was deposited on the $\mathrm{ZnSe}$ crystal by applying $500 \mu \mathrm{L}$ of the adsorbent suspension $(2.5 \mathrm{~g} / \mathrm{L})$ and drying at room temperature. Prior to use, the film was rinsed with DI water to remove loosely deposited particles. A $0.01 \mathrm{~mol} / \mathrm{L} \mathrm{NaCl}$ solution at a predetermined $\mathrm{pH}$ was passed through the flow cell at a 

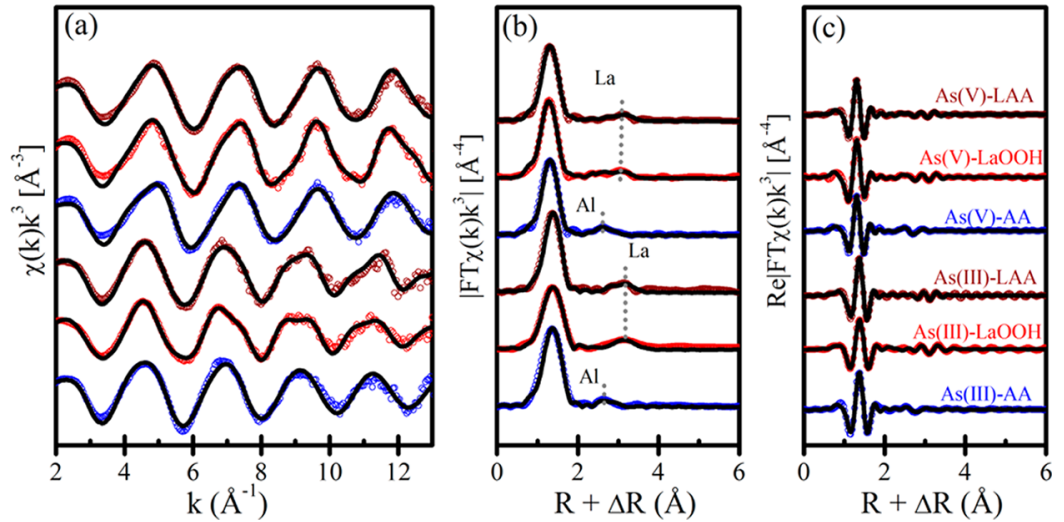

Figure 2. (a) Normalized $k^{3}$-weighted experimental (circles) and simulated (lines) As K-edge EXAFS spectra of As(III) and As(V) adsorption on AA, LAA, and $\mathrm{LaOOH},(b)$ the corresponding Fourier transformed magnitude, and (c) real parts of the Fourier transform.

(a)

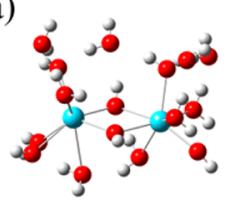

(e)

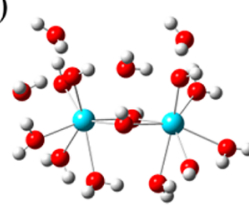

(b)

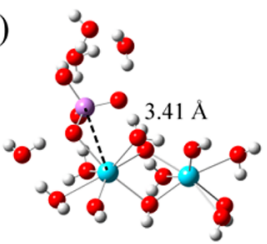

(f)

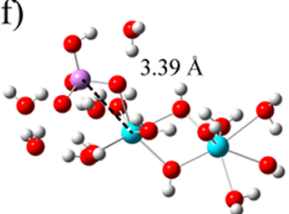

(c)

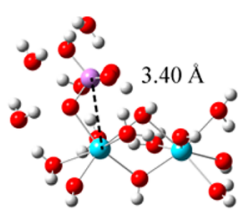

(g)

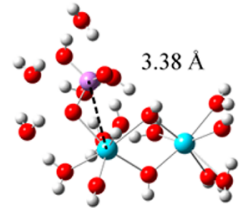

(d)

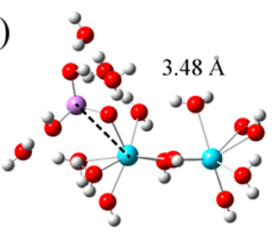

(h)

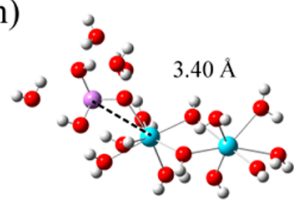

Figure 3. DFT-optimized (b, c, f, g) As(V) and (d, h) As(III) surface configurations on (a-d) neutral and (e-h) positive surfaces. La: cyan, O: red, As: purple, $\mathrm{H}$ : white. The distances between As and La are labeled, and detailed information is listed in Table S8.

rate of $0.5 \mathrm{~mL} / \mathrm{min}$ until there was no further change in the IR spectra. A background spectrum was collected that consisted of the absorbance of the $\mathrm{ZnSe}$ crystal and deposited adsorbents. Then, a $10 \mathrm{mg} / \mathrm{L} \mathrm{As}(\mathrm{V})$ in $0.01 \mathrm{~mol} / \mathrm{L} \mathrm{NaCl}$ solution was passed through the flow cell at the designed $\mathrm{pH}$ values. Spectra were recorded as a function of time until the adsorption reached equilibrium (at least $4 \mathrm{~h}$ ). All samples were purged with $\mathrm{N}_{2}$ in the dark during the spectra collection. The secondorder derivatives were used to locate the peak position in the curve fitting. The peak positions obtained from second derivatives and direct curve fitting were the same within a $5 \mathrm{~cm}^{-1}$ difference.

DFT Calculations. The geometry optimization, IR frequency, and adsorption energy of the As surface complexes were calculated using the Gaussian 09 program $^{21}$ with B3LYP hybrid density function theory (DFT). The 6-311+G (d, p) basis set for As, $\mathrm{H}$, and $\mathrm{O}^{22,23}$ was used with a scale factor of $0.967,{ }^{24}$ and the LanL2DZ basis set was employed for $\mathrm{La}^{25-27}$ with a scale factor of $0.961 .^{24}$ An edge-sharing seven-coordinated hexagonal cluster ${ }^{28,29}$ was used to simulate neutral $\mathrm{La}_{2}(\mathrm{OH})_{6}\left(\mathrm{OH}_{2}\right)_{6} \cdot 4\left(\mathrm{H}_{2} \mathrm{O}\right)$ and positively charged $\mathrm{La}_{2}(\mathrm{OH})_{5}\left(\mathrm{OH}_{2}\right)_{7}$. $4\left(\mathrm{H}_{2} \mathrm{O}\right)$ surfaces. The solvation effect was considered by using an implicit continuum model (IEFPCM) combined with $8 \quad \mathrm{H}_{2} \mathrm{O}$ molecules around $\mathrm{As}(\mathrm{V})$ and $\mathrm{As}(\mathrm{III})$ and $4 \mathrm{H}_{2} \mathrm{O}$ molecules around surface complexes. ${ }^{19,22}$

\section{RESULTS AND DISCUSSION}

Adsorption Kinetics and Isotherms. The adsorption of $\mathrm{As}(\mathrm{III})$ and $\mathrm{As}(\mathrm{V})$ on AA and LAA followed pseudo-second order kinetics $\left(R^{2}>0.98\right.$, Figure $\left.1 \mathrm{a}, \mathrm{b}\right)$, and the fitting parameters are shown in Figure S2 and Table S2. The adsorption isotherms conformed to the Langmuir model with parameters shown in the inset of Figure $1 \mathrm{c}$ and $d$. The material's specific surface area was determined by the
Brunauer-Emmett-Teller (BET) equation as described in our previous report. ${ }^{13}$ The results showed that the BET surface area of LAA $\left(192 \mathrm{~m}^{2} / \mathrm{g}\right)$ is slightly smaller than that of AA $(235$ $\mathrm{m}^{2} / \mathrm{g}$ ). Furthermore, LAA exhibited 2-3 times higher As adsorption capacity than AA (Figure 1). Thus, the specific adsorptions for As(V) and As(III) on LAA (0.137 and 0.048 $\mathrm{mg} / \mathrm{m}^{2}$, respectively) are higher than those on AA (0.039 and $0.021 \mathrm{mg} / \mathrm{m}^{2}$, respectively). However, mechanistic information cannot be explicitly derived from the above macroscopic models. Therefore, spectroscopic techniques were used to decipher the molecular-level interaction mechanisms of As and LAA.

EXAFS Characterization. To explore the role of $\mathrm{Al}$ - and La-oxides in LAA for As removal, we employed EXAFS to characterize the local coordination environment of As(III) and $\mathrm{As}(\mathrm{V})$ on $\mathrm{AA}, \mathrm{LAA}$, and $\mathrm{LaOOH}$. As shown in Figure 2 and Tables S3 and S4, the first FT peak in the As K-edge EXAFS spectra could be fitted with four $\mathrm{O}$ atoms at $1.69 \AA$ for $\mathrm{As}(\mathrm{V})$ samples and three $\mathrm{O}$ atoms at $1.77 \AA$ for As(III) samples, which agrees well with previous reports. ${ }^{30-33}$ The second FT peak for the As(V)-AA sample resulted from $1.5 \mathrm{Al}$ atoms at $3.17 \AA$, and for the As(III)-AA sample, $1.4 \mathrm{Al}$ atoms at $3.23 \AA$. This observation is in accordance with the reported bidentate binuclear configurations for As(III) and As(V) adsorption on $\mathrm{AA}^{33-35}$ Though in a bidentate binuclear configuration, the fact that the coordination numbers for the As-Al shell were lower than two (1.4-1.5) could be attributed to the weak backscattering from the Al element. ${ }^{35}$ For the As- $\mathrm{LaOOH}$ samples, conversely, the second FT peak was ascribed to As-La 

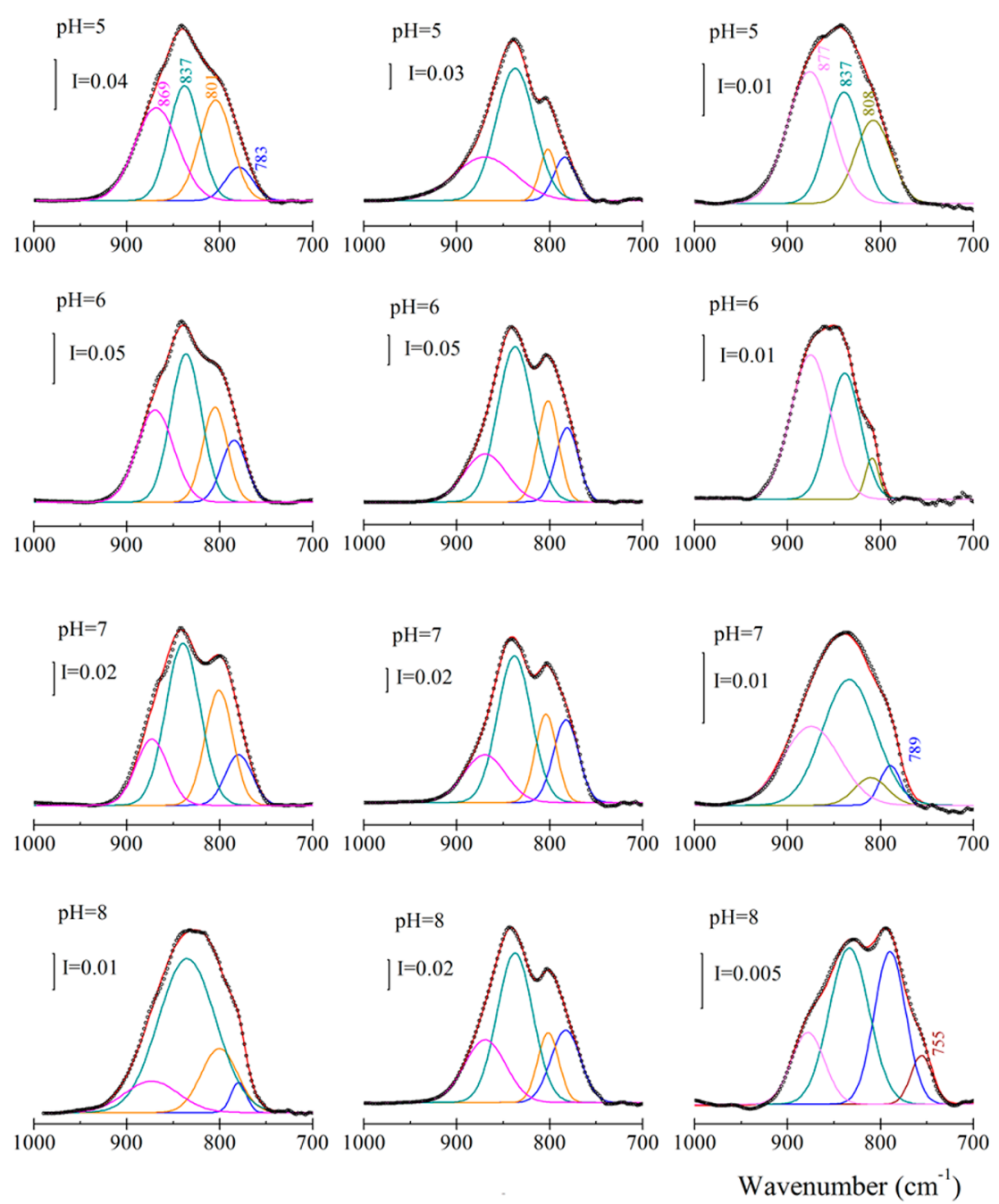

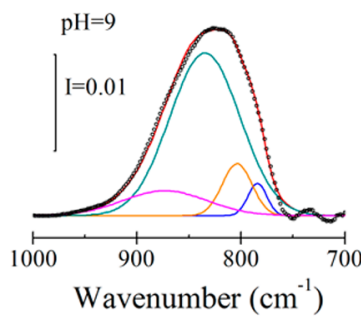

LAA

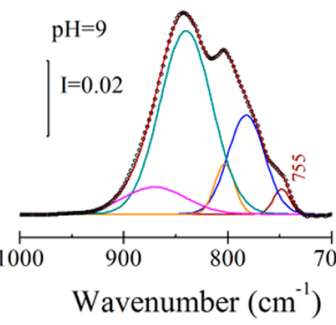

$\mathrm{LaOOH}$

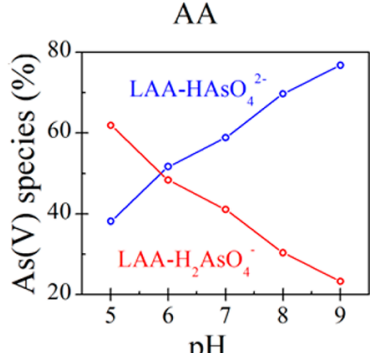

$\mathrm{pH}$

Figure 4. Observed (circles) and curve fitting results (lines) of in situ ATR-FTIR spectra for As(V) surface complexes on LAA (left column), $\mathrm{LaOOH}$ (middle), and AA (right column) as a function of $\mathrm{pH}$. The panel in the bottom right shows the change of As(V) surface species on LAA with fitting results listed in Tables S8-S10. Band positions $\left(\mathrm{cm}^{-1}\right)$ are labeled in the same color as the corresponding lines. IR spectra of As $(\mathrm{V})$ on $\mathrm{AA}$ at $\mathrm{pH} 9$ are absent due to its low signal/noise ratio with low $\mathrm{As}(\mathrm{V})$ loads. As $(\mathrm{V})$ concentration $=10 \mathrm{mg} / \mathrm{L}$; ion strength $=0.01 \mathrm{~mol} / \mathrm{L} \mathrm{NaCl}$; room temperature.

bonding at $3.34 \AA$ with $1.0 \mathrm{La}$ atoms for $\mathrm{As}(\mathrm{V})$, and $3.39 \AA$ with $0.9 \mathrm{La}$ atoms around $\mathrm{As}(\mathrm{III})$, suggesting the formation of a monodentate surface complex. Furthermore, this monodentate configuration did not change in the $\mathrm{pH}$ range 5-9 (Figure S3, Table S5).

Notably, the second FT peaks of the As-LAA samples were observed at the same position as those of As-LaOOH $(R+\Delta R$ $\approx 3.2 \AA$, Figure $2 \mathrm{~b}$ ). This match in terms of atomic distances implies that the second shell for As-LAA samples was La rather than Al. The As-La path was thus used to fit the second FT peak, and the results show that $0.7-1.0 \mathrm{La}$ atoms existed at 3.34-3.42 Å in a monodentate surface configuration (Figure 2,
Tables S3 and S4). For confirmation that Al would not contribute to the second FT peak, the significance of adding an additional As-Al path was evaluated using the F-test. ${ }^{36}$ The Ftest results indicate that the confidence level with the inclusion of the As-Al path in As(V)-LAA (33.3\%) and As(III)-LAA (48.7\%) samples was lower than the required 67\% (Figure S4, Tables S6 and S7), ${ }^{36}$ justifying the conclusion that Al does not exist in the second shell of As-LAA samples.

The As surface structures determined using EXAFS were further confirmed with our DFT calculations (Figure 3, Table S8). For instance, the DFT-calculated La-La distances were 4.04 and $3.99 \AA$ for neutral and positively charged La clusters, 
respectively (Table S8). These values are in reasonable agreement with our previous EXAFS characterization for the average La-La distance $(3.92 \AA)$ on LAA. ${ }^{13}$ The DFTcalculated interatomic distances of As(V)-O (1.72 Å), As(III)-

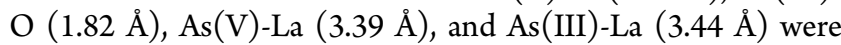
within $0.05 \AA$ difference of those obtained from the EXAFS results (Tables $S 3, S 4$, and S8).

In Situ ATR-FTIR. A major limitation in the EXAFS analysis, however, is its inability to identify the protonation information on As surface complexes. In fact, this structural information is crucial to simulate and predict the As adsorption behaviors. ${ }^{37}$ For elucidation of the protonation of As $(\mathrm{V})$ surface complexes, in situ flow-cell ATR-FTIR was employed to take advantage of its sensitive response to the change in interfacial configuration, especially for protonated oxyanions. ${ }^{38-40}$

The ATR-FTIR spectra clearly resolved the characteristic peaks in the As-O fingerprint range $\left(700-1000 \mathrm{~cm}^{-1}\right)$ upon $\mathrm{As}(\mathrm{V})$ adsorption on AA, LAA, and $\mathrm{LaOOH}$ at $\mathrm{pH}$ 5-9 (Figure 4 and Figure S5). In agreement with the $\mathrm{pH}$ dependence of the As $(\mathrm{V})$ adsorption capacity, ${ }^{37}$ the peak intensity decreased with increasing $\mathrm{pH}$. Furthermore, the peak intensity on LAA was appreciably higher than that on AA in accordance with our adsorption isotherm results (Figure 1c, d).

Significant peak shifts were observed on LAA and AA when the $\mathrm{pH}$ was increased from 5 to 9 (Figure 4 and Figure S5). For example, upon As(V) adsorption on LAA, the highest peak intensity As-O band shifted from $839 \mathrm{~cm}^{-1}$ at $\mathrm{pH} 5$ to 831 $\mathrm{cm}^{-1}$ at $\mathrm{pH} 8$ and further to $829 \mathrm{~cm}^{-1}$ at $\mathrm{pH}$ 9. Conversely, when $\mathrm{As}(\mathrm{V})$ was adsorbed on $\mathrm{AA}$, with the increase in $\mathrm{pH}$, the highest As-O peak at $842 \mathrm{~cm}^{-1}$ at $\mathrm{pH} 5$ shifted to $860 \mathrm{~cm}^{-1}$ at $\mathrm{pH} 6$, moved back to a low frequency $\left(835 \mathrm{~cm}^{-1}\right)$ at $\mathrm{pH} 7$, and was even lower at $792 \mathrm{~cm}^{-1}$ at $\mathrm{pH} 8$.

Generally, the peak shifts of adsorbed oxyanions on metal oxides can be mainly attributed to two structural changes: denticity and protonation. ${ }^{30,41}$ The As denticity on La- and Aloxides was not changed, as evidenced by our EXAFS analysis (Figure S3, Table S5) and previous reports. ${ }^{35}$ Thus, the IR peak shift as a function of $\mathrm{pH}$ should be the result of variations in the protonation of $\mathrm{As}(\mathrm{V})$ surface complexes.

Interestingly, an IR peak shift, such as that observed in this and Persson's study, ${ }^{30}$ could be interpreted as the change in relative intensity of each characteristic band. Each band in the As-O fingerprint range was resolved using curve fitting and DFT calculations. The curve fitting results using the secondorder derivatives are shown in Figure 4 and Table S9-S11. The changes in protonation of $\mathrm{As}(\mathrm{V})$ surface complexes as a function of $\mathrm{pH}$ on LAA, $\mathrm{LaOOH}$, and $\mathrm{AA}$ are discussed in detail in the following three sections.

As(V) Protonation on LAA. The curve fitting results show that four modes at $783,801,837$, and $869 \mathrm{~cm}^{-1}$ were observed at $\mathrm{pH}$ 5-9 upon $\mathrm{As}(\mathrm{V})$ adsorption on LAA (Figure 4). To the best of our knowledge, no articles have reported the characteristic peak positions for $\mathrm{As}(\mathrm{V})$ adsorption on La(hydro)oxides. Hence, to assign these modes, the IR frequencies of optimized As surface structures were further predicted with DFT calculations (Figure 3). The DFT calculated results agreed well with our experimental IR frequencies, which are presented in Table S9.

The DFT-calculated results showed that the modes at 783 and $837 \mathrm{~cm}^{-1}$ could be ascribed to the symmetric and asymmetric vibrations, respectively, of the uncomplexed As-O band in the singly protonated As(V) surface complex (Table S9). Conversely, for doubly protonated As(V) surface species, the symmetric $\left(801 \mathrm{~cm}^{-1}\right)$ and asymmetric $\left(869 \mathrm{~cm}^{-1}\right)$ vibrations exhibited a higher frequency than for the singly protonated ones. This observation is coincident with the change in As-O bond lengths from 1.68 to 1.69 to $1.66 \AA$ as the protonation changed from double to single (Table S8). Such shortened bond lengths imply increased As-O bond strength, which increased the IR peak frequencies from 783 to $801 \mathrm{~cm}^{-1}$ and from 837 to $869 \mathrm{~cm}^{-1}$.

For quantitative analysis of the protonation of As $(\mathrm{V})$ surface species on LAA, the ratio of each peak area to the total area within the fingerprint range $\left(700-1000 \mathrm{~cm}^{-1}\right)$ is summarized in Table S9. Interestingly, the increase in singly protonated surface species with increasing $\mathrm{pH}$ was coincident with the change in the ionization fractions of dissolved $\mathrm{HAsO}_{4}{ }^{-}$species. Moreover, the $\mathrm{pK}_{\mathrm{a}}$ of the transition from doubly to singly protonated As(V) surface species ( 5.8, Figure 4) was lower than for its soluble counterpart $\left(\mathrm{pK}_{\mathrm{a} 2}=6.97\right)$. A similar trend as a function of $\mathrm{pH}$ has been reported for phosphate surface complexes. ${ }^{42}$ In addition, the DFT-calculated adsorption energy confirmed the preference for singly $(-482.4$ to $-233.1 \mathrm{~kJ} / \mathrm{mol})$ over doubly ( 32.3 to $36.9 \mathrm{~kJ} / \mathrm{mol}$ ) protonated surface species (Tables S12 and S13).

As(V) Protonation on $\mathrm{LaOOH}$. As(V) protonation on $\mathrm{LaOOH}$ at $\mathrm{pH} 5-9$ was the same as on LAA because they share the same surface configurations (Figures 3 and 4). Notably, an additional mode at $748 \mathrm{~cm}^{-1}$ was observed upon $\mathrm{As}(\mathrm{V})$ adsorption on $\mathrm{LaOOH}$ at $\mathrm{pH}$ 9. This mode could be attributed to the symmetric vibration of the La-complexed As-O band (As-OLa) upon $\mathrm{HAsO}_{4}{ }^{2-}$ adsorption, which was confirmed by DFT calculations (Tables S9 and S10). In contrast, this mode was not observed on LAA due to the low As load on LAA and the weaker strength of the metal-complexed As-O band than the uncomplexed one. ${ }^{38}$ In addition, the pKa for As surface complexes on $\mathrm{LaOOH}$ was lower than that on LAA because $\mathrm{LaOOH}$, with more positive charge (Figure S1), favors the adsorption of negatively charged As species.

As(V) Protonation on AA. The FTIR spectra for As(V) adsorption on AA at $\mathrm{pH} 5-8$ are shown in the right column of Figure 4 . The bands at 877,837 , and $808 \mathrm{~cm}^{-1}$ were resolved at $\mathrm{pH}$ 5. With the increase in $\mathrm{pH}$, the peak intensity at $808 \mathrm{~cm}^{-1}$ diminished and finally disappeared at $\mathrm{pH} 8$. Instead, two new bands at 789 and $755 \mathrm{~cm}^{-1}$ appeared.

The assignments for As-O bands observed in our study are listed in Table S11. Asymmetric As-O stretching vibrations $\left(837 \mathrm{~cm}^{-1}\right)$ exhibited a higher frequency than the symmetric As-O band $\left(789 \mathrm{~cm}^{-1}\right)$. The band at $755 \mathrm{~cm}^{-1}$ was assigned to As-OAl stretching vibrations in unprotonated As $(\mathrm{V})$ surface species, in agreement with previous reports (740-750 $\left.\mathrm{cm}^{-1}\right) .^{38,43}$ Furthermore, because a proton has a stronger interaction with the As-O bond than a metal, the As-O atomic distance in As-OH is generally longer than in As-OAl. Consequently, the As-OAl band in doubly protonated As surface species $\left(808 \mathrm{~cm}^{-1}\right)$ resulted in a higher frequency than As- $\mathrm{OH}\left(<770 \mathrm{~cm}^{-1}\right){ }^{38,43}$ In concordance with our results, the symmetric As-OFe band has been reported at $802 \mathrm{~cm}^{-1}$ in a previous study. ${ }^{43}$ Notably, the As-OAl with double protonation (808 $\mathrm{cm}^{-1}$ ) exhibited a higher frequency than that for unprotonation $\left(755 \mathrm{~cm}^{-1}\right)$. The two protons interact strongly with oxygen as evidenced by a longer As-O atomic distance in As-OH (1.75-1.77 $\AA$ ) than in As-O (1.66 ̊, Table S8). Such an interaction, in turn, could move the As atom in the $\mathrm{H}_{2} \mathrm{O}_{2}$ As- $\mathrm{O}_{2} \mathrm{Al}_{2}$ surface complex closer to the oxygen atoms bound to $\mathrm{Al}$, and result in a higher frequency band at $808 \mathrm{~cm}^{-1}$. 
Analysis of the change in ratios of each band (Table S11) illustrated three distinct patterns as the $\mathrm{pH}$ increased from 5 to 8: (1) an increase of bands at 837,789 , and $755 \mathrm{~cm}^{-1}$ due to unprotonated surface species, (2) a decreased band at $808 \mathrm{~cm}^{-1}$ due to doubly protonated surface species, and (3) the band at $877 \mathrm{~cm}^{-1}$ due to singly protonated surface species increased its ratio from $\mathrm{pH} 5$ to 6 and then decreased from $\mathrm{pH} 6$ to 8 .

The As-O band of singly protonated As $(\mathrm{V})$ surface species showed a higher frequency $\left(877 \mathrm{~cm}^{-1}\right)$ than that of un- $(837$ $\left.\mathrm{cm}^{-1}\right)$ and doubly protonated $\left(808 \mathrm{~cm}^{-1}\right)$ As $(\mathrm{V})$ surface species. When unprotonated species change to singleprotonation, one of the two uncomplexed As-O bonds becomes As-OH. The addition of a proton moves more electron density to the other As-O bond and thus enhances the As-O bond strength. $^{35,36}$ Conversely, as the surface As $(\mathrm{V})$ species changes from single to double protonation, no uncomplexed As-O bond exists. Under this condition, protonated or metal-complexed As-O bonds (As-OM) would be predominant, resulting in a lower band position than As-O. ${ }^{38,43}$ Thus, the As-O band for doubly protonated $\mathrm{As}(\mathrm{V})$ showed a lower frequency than those of un- and singly protonated $\mathrm{As}(\mathrm{V})$ surface complexes (Figure 4).

The bidentate binuclear As(V) surface complexes occurred with no, single, and double protonation on AA. Table S10 summarizes the $\mathrm{pK}_{\mathrm{a}}$ for these surface complexes. Interestingly, these $\mathrm{pK}_{\mathrm{a}}$ values were much lower than those of their dissolved As $(V)$ counterparts (Figure S6). In a comparison of the $\mathrm{pK}_{\mathrm{a}}$ values on different surfaces, we found that complexes on AA with a bidentate configuration resulted in a lower value $(<5)$ than that on LAA with a monodentate structure $(\sim 5.8)$. The observation suggests that deprotonation may readily occur upon the formation of bidentate complexes.

Predicting Macroscopic Adsorption Behaviors under Microscopic Constraints. The adsorption configurations and reactions derived from our spectroscopic and DFT studies were incorporated in surface complexation modeling to predict the macroscopic adsorption behaviors of As on REMAs. The As $(\mathrm{V})$ and As(III) adsorption isotherms on LAA and AA could be well-predicted with the CD-MUSIC model (Figure S7, Table S14 and S15). The CD-MUSIC fitting results showed that the $\operatorname{logK}$ for $\mathrm{HAsO}_{4}{ }^{2-}$ adsorption on LAA (26.4, Table S14) was higher than that for $\mathrm{H}_{2} \mathrm{AsO}_{4}{ }^{-}(24.3)$ at $\mathrm{pH} 7$, indicating preferential $\mathrm{HAsO}_{4}{ }^{2-}$ adsorption over $\mathrm{H}_{2} \mathrm{AsO}_{4}{ }^{-}$in agreement with our IR and DFT results.

\section{CONCLUSIONS}

In conclusion, multiple complementary spectroscopic techniques and DFT calculations provide evidence for monodentate As surface complexes on LAA, a rare earth-modified adsorbent (REMA). The monodentate configurations may result in a higher site density on REMA surfaces than on bidentate structures for anion adsorption and thus could increase the anion removal capacity. On REMA surfaces, As preferentially adsorbs on rare earth metal oxides rather than the supporting metal oxides. In particular, As(V) on REMAs exhibits singly or doubly protonated configurations. The molecular-level mechanisms should be incorporated to model and predict the adsorption behaviors of oxyanions on REMAs, which is essential in the design and application of these materials.

\section{ASSOCIATED CONTENT}

\section{Supporting Information}

The Supporting Information is available free of charge on the ACS Publications website at DOI: 10.1021/acsami.5b08730.

Zeta potentials, isotherms, kinetics, EXAFS and DFT calculations, FTIR analysis, and CD-MUSIC modeling (PDF)

\section{AUTHOR INFORMATION}

\section{Corresponding Author}

*Tel: +86 106284 9523; fax: +86 106284 9523; e-mail: cyjing@rcees.ac.cn.

Notes

The authors declare no competing financial interest.

\section{ACKNOWLEDGMENTS}

We acknowledge the financial support of the National Basic Research Program of China (2015CB932003), the Strategic Priority Research Program of the Chinese Academy of Sciences (XDB14020201), and the National Natural Science Foundation of China (41373123, 41425016, and 21337004). The EXAFS spectra were acquired at NSRRC BL01C1.

\section{REFERENCES}

(1) Jagtap, S.; Yenkie, M. K.; Labhsetwar, N.; Rayalu, S. Fluoride in Drinking Water and Defluoridation of Water. Chem. Rev. 2012, 112, 2454-2466.

(2) Mohan, D.; Pittman, C. U. Arsenic Removal from Water/ Wastewater Using Adsorbents - a Critical Review. J. Hazard. Mater. 2007, 142, 1-53.

(3) Velazquez-Jimenez, L. H.; Hurt, R. H.; Matos, J.; Rangel-Mendez, J. R. Zirconium-Carbon Hybrid Sorbent for Removal of Fluoride from Water: Oxalic Acid Mediated $\mathrm{Zr}(\mathrm{IV})$ Assembly and Adsorption Mechanism. Environ. Sci. Technol. 2014, 48, 1166-1174.

(4) Kuroda, Y.; Miyamoto, Y.; Hibino, M.; Yamaguchi, K.; Mizuno, N. Tripodal Ligand-Stabilized Layered Double Hydroxide Nanoparticles with Highly Exchangeable CO32-. Chem. Mater. 2013, 25, 2291-2296.

(5) Lebed, P. J.; Savoie, J. D.; Florek, J.; Bilodeau, F.; Lariviere, D.; Kleitz, F. Large Pore Mesostructured Organosilica-Phosphonate Hybrids as Highly Efficient and Regenerable Sorbents for Uranium Sequestration. Chem. Mater. 2012, 24, 4166-4176.

(6) Chen, B.; Zhu, Z.; Liu, S.; Hong, J.; Ma, J.; Qiu, Y.; Chen, J. Facile Hydrothermal Synthesis of Nanostructured Hollow IronCerium Alkoxides and Their Superior Arsenic Adsorption Performance. ACS Appl. Mater. Interfaces 2014, 6, 14016-14025.

(7) Li, Z. J.; Deng, S. B.; Yu, G.; Huang, J.; Lim, V. C. As(V) and As(III) Removal from Water by a Ce-Ti Oxide Adsorbent: Behavior and Mechanism. Chem. Eng. J. 2010, 161, 106-113.

(8) Zhang, Y.; Yang, M.; Dou, X. M.; He, H.; Wang, D. S. Arsenate Adsorption on an Fe-Ce Bimetal Oxide Adsorbent: Role of Surface Properties. Environ. Sci. Technol. 2005, 39, 7246-7253.

(9) Zhang, Y.; Dou, X. M.; Yang, M.; He, H.; Jing, C. Y.; Wu, Z. Y. Removal of Arsenate from Water by Using an Fe-Ce Oxide Adsorbent: Effects of Coexistent Fluoride and Phosphate. J. Hazard. Mater. 2010, $179,208-214$.

(10) Jang, M.; Park, J. K.; Shin, E. W. Lanthanum Functionalized Highly Ordered Mesoporous Media: Implications of Arsenate Removal. Microporous Mesoporous Mater. 2004, 75, 159-168.

(11) Gandhi, M. R.; Meenakshi, S. Preparation and Characterization of La(III) Encapsulated Silica Gel/Chitosan Composite and Its Metal Uptake Studies. J. Hazard. Mater. 2012, 203, 29-37.

(12) Setyono, D.; Valiyaveettil, S. Chemically Modified Sawdust as Renewable Adsorbent for Arsenic Removal from Water. ACS Sustainable Chem. Eng. 2014, 2, 2722-2729. 
(13) Shi, Q. T.; Huang, Y. Y.; Jing, C. Y. Synthesis, Characterization and Application of Lanthanum-Impregnated Activated Alumina for $\mathrm{F}$ Removal. J. Mater. Chem. A 2013, 1, 12797-12803.

(14) Misra, M.; Nayak, D. C. Process for Removal of Selenium and Arsenic from Aqueous Streams. In Google Patents: US5603838 A, 1997.

(15) Newville, M. Ifeffit: Interactive Xafs Analysis and Feff Fitting. J. Synchrotron Radiat. 2001, 8, 322-324.

(16) Ravel, B.; Newville, M. Athena, Artemis, Hephaestus: Data Analysis for X-Ray Absorption Spectroscopy Using Ifeffit. J. Synchrotron Radiat. 2005, 12, 537-541.

(17) Du, J.; Cui, J.; Jing, C. Rapid in Situ Identification of Arsenic Species Using a Portable Fe3O4@Ag SERS Sensor. Chem. Commun. 2014, 50, 347-349.

(18) Jing, C. Y.; Cui, J. L.; Huang, Y. Y.; Li, A. G. Fabrication, Characterization, and Application of a Composite Adsorbent for Simultaneous Removal of Arsenic and Fluoride. ACS Appl. Mater. Interfaces 2012, 4, 714-720.

(19) Yang, Y. L.; Yan, W.; Jing, C. Y. Dynamic Adsorption of Catechol at the Goethite/Aqueous Solution Interface: A MolecularScale Study. Langmuir 2012, 28, 14588-14597.

(20) Yan, W.; Zhang, J. F.; Jing, C. Y. Adsorption of Enrofloxacin on Montmorillonite: Two-Dimensional Correlation ATR/FTIR Spectroscopy Study. J. Colloid Interface Sci. 2013, 390, 196-203.

(21) Frisch, M. J.; Trucks, G. W.; Schlegel, H. B.; Scuseria, G. E.; Robb, M. A.; Cheeseman, J. R.; Scalmani, G.; Barone, V.; Mennucci, B.; Petersson, G. A.; Nakatsuji, H.; Caricato, M.; Li, X.; Hratchian, H. P.; Izmaylov, A. F.; Bloino, J.; Zheng, G.; Sonnenberg, J. L.; Hada, M.; Ehara, M.; Toyota, K.; Fukuda, R.; Hasegawa, J.; Ishida, M.; Nakajima, T.; Honda, Y.; Kitao, O.; Nakai, H.; Vreven, T.; Montgomery, J. A., Jr.; Peralta, J. E.; Ogliaro, F.; Bearpark, M.; Heyd, J. J.; Brothers, E.; Kudin, K. N.; Staroverov, V. N.; Kobayashi, R.; Normand, J.; Raghavachari, K.; Rendell, A.; Burant, J. C.; Iyengar, S. S.; Tomasi, J.; Cossi, M.; Rega, N.; Millam, J. M.; Klene, M.; Knox, J. E.; Cross, J. B.; Bakken, V.; Adamo, C.; Jaramillo, J.; Gomperts, R.; Stratmann, R. E.; Yazyev, O.; Austin, A. J.; Cammi, R.; Pomelli, C.; Ochterski, J. W.; Martin, R. L.; Morokuma, K.; Zakrzewski, V. G.; Voth, G. A.; Salvador, P.; Dannenberg, J. J.; Dapprich, S.; Daniels, A. D.; Farkas, Ö.; Foresman, J. B.; Ortiz, J. V.; Cioslowski, J.; and Fox, D. J. Gaussian 09, revision A.01; Gaussian, Inc.: Wallingford, CT, 2009.

(22) Kubicki, J. D. Comparison of As(III) and As(V) Complexation onto Al- and Fe-Hydroxides. Oxford University Press: Cary, NC, 2005.

(23) Zhu, M. Q.; Paul, K. W.; Kubicki, J. D.; Sparks, D. L. Quantum Chemical Study of Arsenic (III, V) Adsorption on Mn-Oxides: Implications for Arsenic(III) Oxidation. Environ. Sci. Technol. 2009, 43, 6655-6661.

(24) NIST Computational Chemistry Comparison and Benchmark Database; NIST Standard Reference Database Number 101; Release 16a, August 2013. http://cccbdb.nist.gov/ (accessed Oct 21, 2014).

(25) Reed, Z. A.; Duncan, M. A. Photodissociation of Yttrium and Lanthanum Oxide Cluster Cations. J. Phys. Chem. A 2008, 112, 53545362.

(26) Strout, D. L.; Hall, M. B. Structure and Stability of LanthanumCarbon Cations. J. Phys. Chem. A 1998, 102, 641-645.

(27) Zhang, Y. X.; Cai, X.; Zhou, Y.; Zhang, X. X.; Xu, H.; Liu, Z. Q.; Li, X. Y.; Jiang, J. Z. Structures and Spectroscopic Properties of Bis(phthalocyaninato) Yttrium and Lanthanum Complexes: Theoretical Study Based on Density Functional Theory Calculations. J. Phys. Chem. A 2007, 111, 392-400.

(28) Marsella, L.; Fiorentini, V. Structure and Stability of Rare-Earth and Transition-Metal Oxides. Phys. Rev. B: Condens. Matter Mater. Phys. 2004, 69, 172103.

(29) Wyckoff, R. W. G. Crystal Structures. R.E. Krieger Pub. Co.: Malabar, FL, 1982.

(30) Loring, J. S.; Sandstrom, M. H.; Noren, K.; Persson, P. Rethinking Arsenate Coordination at the Surface of Goethite. Chem. Eur. J. 2009, 15, 5063-5072.

(31) Hoffmann, M.; Mikutta, C.; Kretzschmar, R. Arsenite Binding to Natural Organic Matter: Spectroscopic Evidence for Ligand Exchange and Ternary Complex Formation. Environ. Sci. Technol. 2013, 47, 12165-12173.

(32) Mikutta, C.; Kretzschmar, R. Spectroscopic Evidence for Ternary Complex Formation between Arsenate and Ferric Iron Complexes of Humic Substances. Environ. Sci. Technol. 2011, 45, 9550-9557.

(33) Duarte, G.; Ciminelli, V. S. T.; Dantas, M. S. S.; Duarte, H. A.; Vasconcelos, I. F.; Oliveira, A. F.; Osseo-Asare, K. As(III) Immobilization on Gibbsite: Investigation of the Complexation Mechanism by Combining EXAFS Analyses and DFT Calculations. Geochim. Cosmochim. Acta 2012, 83, 205-216.

(34) Ladeira, A. C. Q.; Ciminelli, V. S. T.; Duarte, H. A.; Alves, M. C. M.; Ramos, A. Y. Mechanism of Anion Retention from EXAFS and Density Functional Calculations: Arsenic (V) Adsorbed on Gibbsite. Geochim. Cosmochim. Acta 2001, 65, 1211-1217.

(35) Arai, Y.; Elzinga, E. J.; Sparks, D. L. X-Ray Absorption Spectroscopic Investigation of Arsenite and Arsenate Adsorption at the Aluminum Oxide-Water Interface. J. Colloid Interface Sci. 2001, 235, $80-88$.

(36) Kimling, M. C.; Chen, D. H.; Caruso, R. A. TemperatureInduced Modulation of Mesopore Size in Hierarchically Porous Amorphous $\mathrm{TiO} 2 / \mathrm{ZrO} 2$ Beads for Improved Dye Adsorption Capacity. J. Mater. Chem. A 2015, 3, 3768-3776.

(37) Lee, B.; Lee, S.; Lee, M.; Jeong, D. H.; Baek, Y.; Yoon, J.; Kim, Y. H. Carbon Nanotube-Bonded Graphene Hybrid Aerogels and Their Application to Water Purification. Nanoscale 2015, 7, 6782-6789.

(38) Myneni, S. C. B.; Traina, S. J.; Waychunas, G. A.; Logan, T. J. Vibrational Spectroscopy of Functional Group Chemistry and Arsenate Coordination in Ettringite. Geochim. Cosmochim. Acta 1998, 62, 3499-3514.

(39) Yang, Y.; Duan, J.; Jing, C. Y. Molecular-Scale Study of Salicylate Adsorption and Competition with Catechol at Goethite/Aqueous Solution Interface. J. Phys. Chem. C 2013, 117, 10597-10606.

(40) Tejedor-Tejedor, M. I.; Paredes, L.; Anderson, M. A. Evaluation of ATR-FTIR Spectroscopy as an "in Situ" Tool for Following the Hydrolysis and Condensation of Alkoxysilanes under Rich $\mathrm{H} 2 \mathrm{O}$ Conditions. Chem. Mater. 1998, 10, 3410-3421.

(41) Kubicki, J. D.; Paul, K. W.; Kabalan, L.; Zhu, Q.; Mrozik, M. K.; Aryanpour, M.; Pierre-Louis, A. M.; Strongin, D. R. ATR-FTIR and Density Functional Theory Study of the Structures, Energetics, and Vibrational Spectra of Phosphate Adsorbed onto Goethite. Langmuir 2012, 28, 14573-14587.

(42) Tejedor-Tejedor, M. I.; Anderson, M. A. Protonation of Phosphate on the Surface of Goethite as Studied by CIR-FTIR and Electrophoretic Mobility. Langmuir 1990, 6, 602-611.

(43) Myneni, S. C. B.; Traina, S. J.; Waychunas, G. A.; Logan, T. J. Experimental and Theoretical Vibrational Spectroscopic Evaluation of Arsenate Coordination in Aqueous Solutions, Solids, and at MineralWater Interfaces. Geochim. Cosmochim. Acta 1998, 62, 3285-3300. 